Table 1. Safety profile of treatment-emergent adverse events within the study period

\begin{tabular}{lllll}
\hline & PsA & & AS \\
& N=575 & & N=499 & \\
\cline { 2 - 5 } AE summary, $n(\%)$ & Year 1 & Year 2 & Year 1 & Year 2 \\
\hline Subject with any AE & $239(41.6)$ & $289(50.3)$ & $203(40.7)$ & $247(49.5)$ \\
Subject with any serious AE & $29(5.0)$ & $45(7.8)$ & $29(5.8)$ & $44(8.8)$ \\
Subject with AE leading to discontinuation & $55(9.6)$ & $84(14.6)$ & $47(9.4)$ & $62(12.4)$ \\
Death & $0(0.0)$ & $0(0.0)$ & $0(0.0)$ & $1(0.2)$ \\
AEs of special interest, n (IR per 100 subject-years) & & & \\
Serious infections and infestations & $5(0.96)$ & $9(0.95)$ & $8(1.78)$ & $11(1.33)$ \\
Candida infections & $1(0.19)$ & $2(0.21)$ & $2(0.44)$ & $2(0.24)$ \\
Malignancy & $5(0.96)$ & $7(0.74)$ & N/R & $3(0.36)$ \\
Major adverse cardiovascular events & N/R & $1(0.11)$ & $2(0.44)$ & $3(0.36)$ \\
Inflammatory bowel disease & $\mathrm{N} / \mathrm{R}$ & $\mathrm{N} / \mathrm{R}$ & $1(0.22)$ & $1(0.12)$ \\
\hline
\end{tabular}

$\mathrm{N}$, total number of patients in the safety set; $n$, number of patients with event; $\mathrm{AE}$, adverse events; IR, incidence rate; $N / R$, not reported.

Disclosure of Interests: Uta Kiltz Consultant of: AbbVie, Biocad, Biogen, Chugai, Eli Lilly, Grünenthal, Hexal, Janssen, MSD, Novartis, Pfizer, Roche and UCB, Grant/ research support from: AbbVie, Biocad, Biogen, Chugai, Eli Lilly, Grünenthal, Hexal, Janssen, MSD, Novartis, Pfizer, Roche and UCB, Petros Sfikakis Consultant of: AbbVie, Amgen, Boehringer Ingelheim, Celgene, Eli-Lilly, Janssen, Novartis and Pfizer, Grant/research support from: AbbVie, Amgen, Boehringer Ingelheim, Celgene, EliLilly, Janssen, Novartis and Pfizer, Nicola Gullick Speakers bureau: AbbVie, Celgene, Eli Lilly, Izana, Janssen, Novartis, UCB., Consultant of: AbbVie, Celgene, Eli Lilly, Izana, Janssen, Novartis, UCB., Grant/research support from: AbbVie, Celgene, Eli Lilly, Izana, Janssen, Novartis, UCB., Athina Theodoridou Consultant of: UCB, Amgen, Novartis, Jan Brandt-Juergens Speakers bureau: AbbVie, Pfizer, Roche, Sanofi-Aventis, Novartis, Lilly, MSD, UCB, BMS, Janssen, and Medac, Consultant of: AbbVie, Pfizer, Roche, Sanofi-Aventis, Novartis, Lilly, MSD, UCB, BMS, Janssen, and Medac, Eric Lespessailles Speakers bureau: Amgen, Expanscience, Lilly and MSD, Consultant of: Amgen, Expanscience, Lilly and MSD, Grant/research support from: Abbvie, Amgen, Lilly, MSD and UCB, Rasho Rashkov Speakers bureau: AbbVie, Amgen, Pfizer, Novartis, MSD, UCB, Roche and Janssen, Consultant of: AbbVie, Amgen, Pfizer, Novartis, MSD, UCB, Roche and Janssen, Jenny Fang Employee of: Novartis, Effie Pournara Shareholder of: Novartis, Employee of: Novartis, Barbara Schulz Employee of: Novartis, Piotr Jagiello Employee of: Novartis, Karl Gaffney Speakers bureau: AbbVie, Celgene, Lilly, Pfizer, Gilead, MSD, Novartis and UCB, Consultant of: AbbVie, Celgene, Lilly, Pfizer, Gilead, MSD, Novartis and UCB, Grant/ research support from: AbbVie, Celgene, Lilly, Pfizer, Gilead, MSD, Novartis and UCB. DOI: 10.1136/annrheumdis-2021-eular.2263

\section{POS0235 COMPARISON OF AXIAL AND PERIPHERAL MANIFESTATIONS IN PATIENTS WITH PSORIATIC ARTHRITIS AND ANKYLOSING SPONDYLITIS IN UPADACITINIB CLINICAL TRIALS}

X. Baraliakos ${ }^{1}$, A. Deodhar ${ }^{2}$, R. Ranza ${ }^{3}$, S. Rednic ${ }^{4,5}$, F. Ciccia $^{6}$ F. Ganz ${ }^{7}$, T. Gao ${ }^{7}$, A. Lertratanakul ${ }^{7}$, I. H. Song ${ }^{7}$, A. Ostor ${ }^{8}$, L. C. Coates ${ }^{9}$. ${ }^{1}$ Rheumazentrum Ruhrgebiet Herne, Ruhr-University Bochum, Rheumatology, Bochum, Germany; ${ }^{2}$ Oregon Health \& Science University, Rheumatology, Portland, Oregon, United States of America; ${ }^{3}$ Universidade Federal de Uberlândia, Serviço de Reumatología, Uberlândia, Minas Gerais, Brazil; ${ }^{4}$ Emergency Clinical County Hospital, Rheumatology, Cluj-Napoca, Romania; ${ }^{5} /$ luliu Hatieganu University of Medicine and Pharmacy, Rheumatology, ClujNapoca, Romania; ${ }^{6}$ University of Campania Luigi Vanvitelli, Rheumatology, Caserta, Italy: ${ }^{7}$ AbbVie Inc., Immunology, North Chicago, Illinois, United States of America; ${ }^{8}$ Monash University, Cabrini Hospital \& Emeritus Research, Rheumatology, Melbourne, Victoria, Australia; ${ }^{9}$ University of Oxford, Rheumatology, Oxford, United Kingdom

Background: Axial, peripheral, and other disease manifestations often overlap between psoriatic arthritis (PsA) and ankylosing spondylitis (AS). Upadacitinib (UPA) is an oral Janus kinase inhibitor under evaluation for the treatment of PsA and AS. Objectives: To describe and compare baseline characteristics and UPA efficacy across 4 subgroups of patients (pts) from clinical trials: active PsA (with/without axial involvement) and active AS (with/without peripheral involvement).

Methods: Baseline characteristics and efficacy of UPA in reducing axial and peripheral signs and symptoms were assessed via an integrated analysis across the $4 \mathrm{pt}$ subgroups from the SELECT-PsA $1,{ }^{1}$ SELECT-PsA $2,{ }^{2}$ and SELECT-AXIS ${ }^{3}$ studies. Analyses of baseline characteristics included pts in the UPA $15 \mathrm{mg}$ once daily (QD), UPA $30 \mathrm{mg}$ QD, and placebo (PBO) groups; efficacy analyses included pts in the UPA $15 \mathrm{mg}$ QD group only. Axial involvement in PsA (axial PsA) was determined by investigator assessment. Peripheral involvement in AS was defined based on presence of tender or swollen joints (TJC68 $>0$ or SJC66 $>0$ ), or presence of enthesitis at baseline (Maastricht Ankylosing Spondylitis Enthesitis Score $>0$ ).

Results: 2102 pts (UPA $15 \mathrm{mg}$; UPA $30 \mathrm{mg}$; PBO) were evaluated across the 4 subgroups (PsA [with/without axial involvement]: 626/1289; AS [with/without peripheral involvement]: 135/52). $33 \%$ of pts with PsA had axial PsA; $72 \%$ of pts with AS had peripheral symptoms. Pts with axial PsA had higher peripheral join (TJC68 and SJC66) and skin (psoriasis) burden than pts with AS with peripheral involvement $(p<0.0001)$. Pts with AS with peripheral involvement had significantly greater overall pain (pt's assessment of pain; $p=0.0002$ ) and back pain (BASDAI Q2; $p<0.0001$ ) scores, and higher total BASDAI $(p=0.0076)$ and ASDAS $(p=0.0351)$ scores than pts with axial PsA; physician's global assessment of disease activity, and peripheral pain and tenderness (BASDAI Q3 and Q4) were numerically similar for these 2 subgroups (Table 1). The efficacy of UPA $15 \mathrm{mg}$ (measured using ASDAS and BASDAI) was generally consistent across the $4 \mathrm{pt}$ subgroups regardless of peripheral or axial involvement (Figure 1)

Conclusion: Pts with PsA with axial involvement and pts with active AS showed some differences in baseline characteristics but similar improvements versus placebo with UPA $15 \mathrm{mg}$ QD.

\section{REFERENCES:}

[1] McInnes I, et al. Ann Rheum Dis 2020;79(Suppl 1):16-17; 2. Genovese MC et al. Ann Rheum Dis 2020;79(Suppl 1):139; 3. van der Heijde D, et al. Lancet 2019;394:2108-17.

Table 1. Baseline demographics, medical history, and disease characteristics

\begin{tabular}{|c|c|c|c|c|c|}
\hline $\begin{array}{l}\text { Mean (SD), unless } \\
\text { otherwise specified }\end{array}$ & $\begin{array}{l}\text { PsA with } \\
\text { axial } \\
\text { involve- } \\
\text { ment } \\
\mathrm{n}=626\end{array}$ & $\begin{array}{l}\text { PsA with- } \\
\text { out axial } \\
\text { involvement } \\
n=1289\end{array}$ & $\begin{array}{l}\text { AS with } \\
\text { peripheral } \\
\text { t involvement } \\
n=135\end{array}$ & $\begin{array}{l}\text { AS without } \\
\text { peripheral } \\
\text { involvement } \\
n=52\end{array}$ & $\begin{array}{l}\text { p-value } \\
\text { (PsA with axial } \\
\text { involvement versus } \\
\text { AS with peripheral } \\
\text { involvement) }\end{array}$ \\
\hline Male, n (\%) & 300 (47.9) & $583(45.2)$ & $88(65.2)$ & $44(84.6)$ & 0.0003 \\
\hline Age, years & $50.7(12.6)$ & 52.0 & $46.6(12.7)$ & $42.2(11.4)$ & 0.0008 \\
\hline $\begin{array}{l}\text { Body mass index, } \\
\mathrm{kg} / \mathrm{m}^{2}\end{array}$ & $30.3(7.1)$ & $30.7(6.8)^{\mathrm{a}}$ & $26.7(4.9)$ & $26.8(5.2)$ & * \\
\hline $\begin{array}{l}\text { Duration of disease } \\
\text { symptoms, years }\end{array}$ & $11.2(9.3)^{\mathrm{b}}$ & $10.4(9.5)^{\mathrm{a}}$ & $14.6(10.9)$ & $14.0(10.6)$ & 0.0009 \\
\hline $\begin{array}{l}\text { Duration of disease } \\
\text { since diagnosis, } \\
\text { years }\end{array}$ & $7.7(8.0)$ & $7.3(8.0)$ & $7.0(9.2)$ & $6.8(8.4)$ & 0.3738 \\
\hline TJC68 & $23.6(16.4$ & $20.6(14.6)$ & $5.3(8.2)$ & 0 & * \\
\hline SJC66 & $11.9(9.0)$ & $11.2(8.2)$ & $1.5(3.2)$ & 0 & * \\
\hline Psoriasis, n (\%) & $616(98.4)$ & 1269 & $7(5.2)$ & 0 & * \\
\hline $\begin{array}{l}\text { Uveitis, } \mathrm{n}(\%) \\
\text { Inflammatory bo }\end{array}$ & $1(0.2)$ & $5(0.4)$ & $3(2.2)$ & $1(1.9)$ & 0.0191 \\
\hline disease, n (\%) & $10(1.6)$ & $13(1.0)$ & $2(1.5)$ & $2(3.8)$ & 1.0000 \\
\hline PhGA & $6.7(1.7)$ & $6.5(1.7)$ & $6.7(1.5)^{\mathrm{c}}$ & $6.9(1.7)^{b}$ & 0.6960 \\
\hline Pain, VAS 0-10 & $6.3(2.0)^{b}$ & $6.1(2.2)^{d}$ & $6.9(1.6)^{\mathrm{a}}$ & $6.8(1.7)^{\mathrm{a}}$ & 0.0002 \\
\hline ASDAS(CRP) & $3.4(1.0)^{\mathrm{e}}$ & $3.1(1.0)^{f}$ & $3.5(0.7)^{\mathrm{a}}$ & $3.7(0.8)^{\mathrm{a}}$ & 0.0351 \\
\hline BASDAI (Total score) & $6.0(2.1)^{\mathrm{e}}$ & $5.5(2.2)^{\dagger}$ & $6.4(1.6)$ & $6.3(1.8)^{a}$ & 0.0076 \\
\hline $\begin{array}{l}\text { BASDAI Q2 (Back } \\
\text { pain) }\end{array}$ & $6.1(2.7)^{\mathrm{e}}$ & $4.8(3.2)^{f}$ & $7.2(1.7)$ & $7.2(1.6)^{\mathrm{a}}$ & * \\
\hline $\begin{array}{l}\text { BASDAI Q3 } \\
\text { (Peripheral pain/ } \\
\text { swelling) } \\
\text { BASDAI Q4 }\end{array}$ & $6.3(2.4)^{\mathrm{e}}$ & $6.0(2.6)^{f}$ & $5.9(2.4)$ & $5.5(2.4)^{\mathrm{a}}$ & 0.0747 \\
\hline (Tenderness) & $5.8(2.6)^{\mathrm{e}}$ & $5.6(2.7)^{f}$ & $6.1(2.5)$ & $5.7(2.4)^{\mathrm{a}}$ & 0.3196 \\
\hline
\end{tabular}

Acknowledgements: AbbVie funded this study; contributed to its design; participated in data collection, analysis, and interpretation of the data; and participated in the writing, review, and approval of the abstract. No honoraria or payments were made for authorship. Medical writing support was provided by Grant Thomas Kirkpatrick, MSc, of 2 the Nth (Cheshire, UK), and was funded by AbbVie.

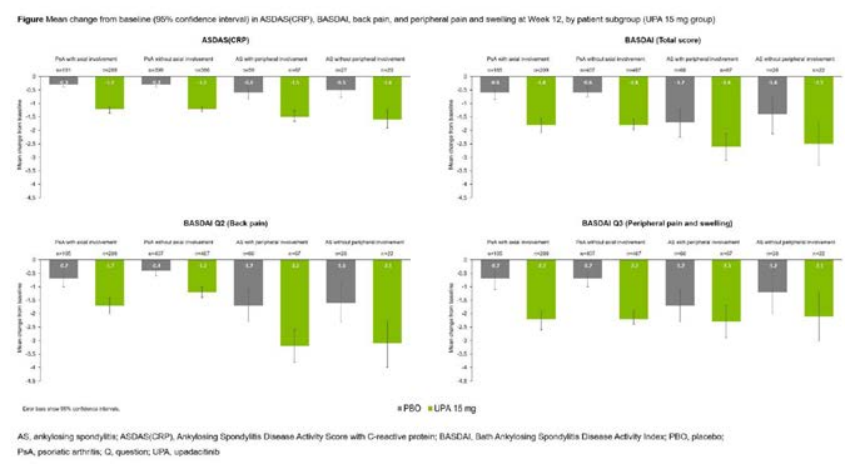

Disclosure of Interests: Xenofon Baraliakos Speakers bureau: AbbVie Bristol-Myers Squibb, Celgene, Chugai, Eli Lilly, Galapagos, Gilead, MSD, Novartis, Pfizer, and UCB, Consultant of: AbbVie, Bristol-Myers Squibb, Celgene, Chugai, Eli Lilly, Galapagos, Gilead, MSD, Novartis, Pfizer, and UCB, Grant/research support from: AbbVie, Bristol-Myers Squibb, Celgene Chugai, Eli Lilly, Galapagos, Gilead, MSD, Novartis, Pfizer, and UCB, Atul 
Deodhar Speakers bureau: AbbVie, Amgen, Boehringer Ingelheim, Bristol-Myers Squibb, Eli Lilly, GSK, Janssen, Novartis, Pfizer, and UCB, Consultant of: AbbVie, Amgen, Boehringer Ingelheim, Bristol-Myers Squibb, Eli Lilly, GSK, Janssen, Novartis, Pfizer, and UCB, Grant/research support from: AbbVie, Eli Lilly, GSK, Novartis, Pfizer, and UCB, R Ranza Speakers bureau: AbbVie, Janssen, Novartis, and Pfizer, Consultant of: AbbVie, Janssen, Novartis, and Pfizer, Simona Rednic: None declared, francesco ciccia Speakers bureau: AbbVie, Bristol-Myers Squibb, Celgene, Novartis, Pfizer, UCB, and Werfen, Consultant of: AbbVie, Bristol-Myers Squibb, Celgene, MSD, Novartis, Pfizer, and UCB, Grant/research support from: AbbVie, Celgene, Chugai, Pfizer, and UCB, Fabiana Ganz Shareholder of: May own stock or options in AbbVie, Employee of: AbbVie, Tianming Gao Shareholder of: May own stock or options in AbbVie, Employee of: AbbVie, Apinya Lertratanakul Shareholder of: May own stock or options in AbbVie, Employee of: AbbVie, In-Ho Song Shareholder of: May own stock or options in AbbVie, Employee of: AbbVie, Andrew Ostor Speakers bureau: AbbVie, Bristol-Myers Squibb, Eli Lilly, Gilead, MSD, Novartis, Pfizer, and Roche, Consultant of: AbbVie, Bristol-Myers Squibb, Eli Lilly, Gilead, MSD, Novartis, Pfizer, and Roche, Laura C Coates: None declared.

DOI: 10.1136/annrheumdis-2021-eular.2105

\section{Clinical aspects of spondyloarthritis}

\begin{tabular}{|l|l}
\hline POSO236 & COMPARISON OF WORK PRODUCTIVITY \\
OUTCOMES BETWEEN CHRONIC BACK PAIN \\
PATIENTS WITH AND WITHOUT A DIAGNOSIS OF \\
AXIAL SPONDYLOARTHRITIS AFTER 2-YEAR \\
PROTOCOLISED FOLLOW-UP: DATA FROM THE \\
SPONDYLOARTHRITIS CAUGHT EARLY COHORT
\end{tabular}

A. Boel ${ }^{1}$, M. Van Lunteren ${ }^{1}$, K. M. Fagerli ${ }^{2}$, R. Ramonda ${ }^{3}$, S. Exarchou ${ }^{4}$ M. Van de Sande ${ }^{5}$, F. A. Van Gaalen', D. Van der Heijde'. ${ }^{1}$ Leiden University Medical Centre, Rheumatology, Leiden, Netherlands; ${ }^{2}$ Diakonhjemmet Hospital, Rheumatology, Oslo, Norway: ${ }^{3}$ University of Padova, Rheumatology Unit, Padova, Italy; ${ }^{4}$ Lund University, Clinical Sciences, Section of Rheumatology, Malmö, Sweden; ${ }^{5}$ Amsterdam University Medical Center, Rheumatology and Clinical Immunology, Amsterdam, Netherlands

\section{Background:}

Objectives: To compare work-productivity and activity impairment outcomes between chronic back pain (CBP) patients with and without an axSpA diagnosis after two years of protocollised follow-up.

Methods: Work productivity was assessed using the Work Productivity and Activity Impairment (WPAI) general health version 1.0 questionnaire. Presenteeism was defined as a reduction in performance due to disease while at work; absenteeism was time missed from work due to disease; work productivity loss (WPL) was a combined measure of presenteeism and absenteeism; and activity impairment was impairment due to disease in all non-work related activities. All WPAI outcomes were presented as percentages; higher scores implying greater impairment. Additionally, the proportion of patients with any $(>0 \%)$ absenteeism, presenteeism, WPL and activity impairment were given.

This study used data from the SPACE cohort, which consists of patients with CBP ( $\geq 3$ months $<2$ years) suspected of axSpA. Analyses were restricted to patients with a diagnosis axSpA or no axSpA (CBP group) with a level of confidence $\geq 7$ (on a 0-10 scale) after locally read imaging. Additionally, data had to be available on the WPAI questionnaire at both timepoints. Assessment of presenteeism, absenteeism and WPL was restricted to the working population, defined as having paid work at baseline and 2-year follow-up. Activity impairment was assessed for the entire study population.

Regression models were used to test the difference between groups at two-year follow-up for all WPAI variables. Baseline WPAI values and NSAID-use over time were tested as confounders.

Results: Patients with a diagnosis of axSpA were more frequently male (56\% vs $30 \%$ ) and HLA-B27 positive ( $73 \%$ vs $31 \%$ ) and had more SpA features at baseline compared to the patients with CBP [mean (SD) 5(2) vs 3(1)]. Age, symptom duration, NSAID-use and the percentage of patients with paid work at baseline were similar between groups.

The population having paid work at baseline and 2 years consisted of 124 patients $(69 \%)$ in the axSpA group and 52 patients $(70 \%)$ in the CBP group. In both groups the proportion of patients with any as well as the mean WPL reduces. This reduction was apparent in both presenteeism and absenteeism. Nevertheless, presenteeism, WPL and activity impairment were significantly higher at two-year follow-up in the group with CBP (Table 1). In these regression models with baseline values and NSAID-use over time as covariates, axSpA was an independent predictor of lower presenteeism, WPL and activity impairment at two-year follow-up.
Table 1. Work-productivity outcomes at baseline and two-year follow-up for the group with a diagnosis of axSpA and the group without a diagnosis.

\begin{tabular}{llllll}
\hline & $\begin{array}{l}\text { Diagnosis axSpA } \\
\text { Baseline 2 years }\end{array}$ & $\begin{array}{l}\text { CBP } \\
\text { Baseline 2 years }\end{array}$ & $\begin{array}{l}\text { p-values } \\
\text { between groups } \\
\text { at 2yrs }\end{array}$ \\
\hline Working population & $\mathrm{N}=124$ & $\mathrm{~N}=52$ & & \\
\hline Presenteeism, mean (SD) \% & $31(28)$ & $18(24)^{\dagger}$ & $40(29)$ & $30(30)^{\dagger}$ & $\mathrm{p}=0.003^{*}$ \\
Presenteeism present, \% & 73 & 52 & 87 & 67 & \\
Absenteeism, mean (SD) \% & $7(18)$ & $4(14)^{\dagger}$ & $12(25)$ & $6(21)^{\dagger}$ & $\mathrm{p}=0.334$ \\
Absenteeism present, \% & 22 & 7 & 27 & 12 & \\
Overall work impairment, & $33(29)$ & $22(27)^{\dagger}$ & $43(30)$ & $35(33)$ & $\mathrm{p}=0.005^{\star}$
\end{tabular}

mean (SD) \%

$\begin{array}{lllll}\text { Overall work impairment } & 72 & 46 & 87 & 65\end{array}$

present, \%

Total population

Activity impairment,

$\mathrm{N}=181$

mean (SD) \%

$\begin{array}{lllll}\text { Activity impairment, } \mathrm{n}(\%) & 86 & 64 & 93 & 70\end{array}$

* Significant difference between groups at two years; after correction for baseline values and NSAID use over time ${ }^{\dagger}$ Significant improvement within group over time

Conclusion: Despite significant improvements in both groups, patients with axSpA have significantly better work-related outcomes after two years of protocolised follow-up compared to those without axSpA.

Disclosure of Interests: None declared

DOI: 10.1136/annrheumdis-2021-eular.351

\section{POS0237 GUT DYSBIOSIS LINKED TO WORSE DISEASE STATUS} IN AXIAL SPONDYLOARTHRITIS

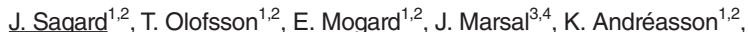
M. Geijer ${ }^{5,6,7}$, L. E. Kristensen ${ }^{1,8}$, E. Lindqvist ${ }^{1,2}$, J. K. Wallman ${ }^{1,2}$. $^{1}$ Lund University, Department of Clinical Sciences Lund, Rheumatology, Lund, Sweden; ${ }^{2}$ Skåne University Hospital, Department of Rheumatology, Lund, Sweden; ${ }^{3}$ Lund University, Department of Immunology, EMV, Lund, Sweden; ${ }^{4}$ Skåne University Hospital, Department of Gastroenterology, Lund, Sweden; ${ }^{5}$ University of Gothenburg, Sahlgrenska Academy, Institute of Clinical Sciences, Department of Radiology, Gothenburg, Sweden; ${ }^{6}$ Sahlgrenska University Hospital, Department of Radiology, Gothenburg, Sweden; ${ }^{7}$ Lund University, Department of Clinical Sciences, Lund, Sweden; ${ }^{8}$ Copenhagen University Hospital, Frederiksberg and Bispebjerg, Parker Institute, Department of Rheumatology, Copenhagen, Denmark

Background: Based on clinical and genetic associations, axial spondyloarthritis (axSpA) and inflammatory bowel disease (IBD) are suspected to have a linked pathogenesis. Gut dysbiosis, intrinsic to IBD, has also been observed in axSpA. It is, however, not established to what degree gut dysbiosis is associated with axSpA disease severity. Objectives: To compare presence and degree of gut dysbiosis between axSpA patients and controls, and to explore whether gut dysbiosis is associated with axSpA disease activity, function and pain

Methods: The GA-map Dysbiosis Test (Genetic Analysis, Oslo, Norway) was used to identify and grade gut dysbiosis based on faecal samples from 44 non-radiographic axSpA (nr-axSpA; ASAS criteria) and 88 ankylosing spondylitis (AS; modified New York criteria) patients without IBD, consecutively enrolled in a population-based cohort study, and from 46 controls without rheumatic disease or IBD (frequency-matched to the patients for age/sex). The GA-map Dysbiosis Test is a validated method grading microbiota aberration on a 1-5 scale (Dysbiosis Index, $\mathrm{DI}$ ), where $\geq 3$ denotes dysbiosis. Analysis of covariance (ANCOVA) was used to compare DI between axSpA patients (nr-axSpA and AS combined) and controls, adjusted for age, sex, body mass index (BMI) and smoking. Within the axSpA group, disease activity (ASDAS-CRP; BASDAI), function (BASFI) and pain (VAS pain) were compared between patients with various DI levels by One-way analysis of variance (ANOVA) or Kruskal-Wallis test, as appropriate. Finally, axSpA patients were subdivided by presence of dysbiosis (DI $\geq 3$ vs. $<3$ ) followed by comparison of ASDAS-CRP, BASDAI, BASFI, VAS pain and Evaluator's global assessment of disease activity (EvalGlobal; 0-4: remission-maximal) by ANCOVA. Analyses were conducted unadjusted and adjusted for age, sex, BMI, smoking, axSpA subtype, gut inflammation (faecal calprotectin $\geq 50 \mathrm{mg} / \mathrm{kg}$ ), irritable bowel syndrome symptoms (ROME III criteria), ASAS 3-month NSAID score and cs/bDMARD treatment. Results: Characteristics of the patients/controls are shown in the Table 1. Gut dysbiosis $(\mathrm{DI} \geq 3)$ was observed in $33 \%$ of axSpA patients and $17 \%$ of controls. DI was significantly higher among the patients $(\beta$-estimate [bootstrapped $95 \% \mathrm{Cl}$ ] for the between-group difference: 0.34 [0.04-0.65]; $p=0.027$ ). In the axSpA group, higher DI was associated with worse scores in all assessed outcomes (Figure 1, panel A). Moreover, presence of dysbiosis ( $\mathrm{DI} \geq 3$ ) was associated with worse ASDAS-CRP, BASDAI, BASFI, VAS pain and EvalGlobal (Figure 1, panel B; EvalGlobal not shown in the Figure: unadjusted $\beta$ [bootstrapped $95 \% \mathrm{Cl}]$ : 0.32 [0.09-0.55], adjusted: 0.28 [0.03-0.52] for patients with $\mathrm{DI} \geq 3$ vs. $<3$ ), with between-group differences remaining significant after adjustment, except for ASDAS-CRP $(p=0.079)$ and VAS pain $(p=0.064)$.

Conclusion: Gut dysbiosis, present to a higher degree in axSpA patients than controls, is associated with worse axSpA disease activity and function. These 